ISSN 2227-7102

www.mdpi.com/journal/education

Article

\title{
The Use of a Learning Management System (LMS) to Serve as the Virtual Common Space of a Network for the Scholarship of Teaching and Learning (SoTL) in an Academic Department
}

Nicolette Bradley ${ }^{1, *}$, Lorraine Jadeski ${ }^{2}$, Genevieve Newton ${ }^{2}$, Kerry Ritchie ${ }^{2}$, Scott Merrett ${ }^{3}$ and William Bettger ${ }^{2}$

1 School of Kinesiology \& Health Science, York University, 4700 Keele St., Toronto, ON, M3J 1P3, Canada

2 Department of Human Health and Nutritional Sciences, University of Guelph, Guelph, ON, N1G 2W1, Canada; E-Mails: ljadeski@uoguelph.ca (L.J.);

Gen.Newton@GuelphHumber.ca (G.N.); ritchiek@uoguelph.ca (K.R.); wbettger@uoguelph.ca (W.B.)

3 Centre for Open Learning and Educational Support, University of Guelph, Guelph, ON, N1G 2W1, Canada; E-Mail: smerrett@uoguelph.ca

* Author to whom correspondence should be addressed; E-Mail: bradleyn@ yorku.ca;

Tel.: +416-736-2100 ext. 33237; Fax: +416-736-5774.

Received: 29 January 2013; in revised form: 1 April 2013 / Accepted: 23 April 2013 /

Published: 15 May 2013

Abstract: Traditionally, undergraduate curriculum committees, consisting of appointed faculty and student representatives, have served as the sole departmental vehicle for investigating, discussing and promoting the scholarship of teaching and learning (SoTL) within an academic department. However, with the universal demand for greater accountability on all aspects of evidence-based teaching and on the totality of student learning and career outcomes, some academic departments have encouraged the formation of additional organizations to support their SoTL mandate. In the Department of Human Health and Nutritional Sciences, the approach taken was to combine the interests of the faculty who had a sustained interest in the "scholarship of knowledge translation and transfer" in the health sciences with those who had a developing interest in SoTL. These faculty members would then form the foundation of a "network" which has been called the $\mathrm{K}^{*} \mathrm{~T} 3$ net. The virtual common space of the network is on a Learning Management System 
(LMS) site which is accessed by all faculty members in the network and by a growing number of staff and senior PhD students in the department. The features and potential uses of the $\mathrm{K}^{*} \mathrm{~T} 3$ net website will be discussed. The development of the $\mathrm{K}^{*} \mathrm{~T} 3$ net has already supported the proposal for a new undergraduate course on SoTL and is opening the possibility for graduate students to add a SoTL component to their thesis research.

Keywords: SoTL; learning management system; faculty network; online forum; knowledge transfer; knowledge translation; evidence-based teaching

\section{Introduction}

Over the past decade, there has been an increasing call for change in the way universities view and enact their teaching and research mandates. Within the teaching domain, voices at the local university [1] and at the national/international [2] levels have eloquently articulated the need for a more accountable, scholarly and learner-centered approach to undergraduate education. Within the research domain, the major Canadian research funding agencies, also known as the Tri-council agencies (SSHRC, NSERC, CIHR) have made it clear that grantees are required to go beyond the discovery of knowledge and produce significant, accountable, scholarly activity in knowledge transfer and translation (i.e., mobilization/exchange of knowledge, also known as KTT). The "slow explosion" of change is underway at Canadian universities [3,4] and it is affecting the professional lives of all members of the university community.

These new dimensions of scholarship follow on the seminal work of Boyer [5], which called for an infusion of scholarship into all aspects of the professional lives of faculty at universities. While the proposed changes are highly desirable for the education of undergraduate and graduate students and for society at large, faculty (in the natural sciences disciplines in particular) are generally not trained in graduate school or post-doctoral activities to be competent in the scholarship of teaching and learning or of knowledge transfer and translation [6-8]. With pressures mounting for rapid change in universities, how can existing faculty, staff and students, facilitate and guide that change? How can they create a multi-dimensional common space for learning at the grassroots level (in order to foster and support professional development in these new areas of scholarship) and have the institutional infrastructure and policies needed to encourage and reward this activity [9]?

Traditionally, undergraduate curriculum committees, consisting of appointed faculty and student representatives, have served as the sole departmental vehicle for investigating, discussing and promoting the scholarship of teaching and learning (SoTL) within an academic department. However, with the universal demand for greater accountability on all aspects of evidence-based teaching and on the totality of student learning and career outcomes, some academic departments have encouraged the formation of additional organizations to support their SoTL mandate. In the Department of Human Health and Nutritional Sciences at the University of Guelph (UoG), the approach taken was to combine the interests of the faculty who had a previous interest in the SoTL and the scholarship of knowledge transfer and translation (hereafter to be referred to as SoKTT) in the health sciences with those who had a developing interest in these areas. These faculty members would then form the 
foundation of a "network" which has been called the K*T3net. The name of the network was formed from $\mathrm{K}^{*}$, which is used increasingly in the academic community as an overarching term which encompasses several related domains which include, but are not limited to, knowledge brokerage, knowledge management, knowledge transfer and translation [10]. The second part of the network name (T3) represents knowledge transfer, translation and teaching.

The central common space of the network is a virtual space within an LMS platform already in use by the university for course websites (specifically, the LMS in use at the UoG is Desire2Learn (D2L, Kitchener, ON, CAN). The $\mathrm{K}^{* \mathrm{~T} 3 n e t}$ virtual space (hereafter referred to as the $\mathrm{K}^{*} \mathrm{~T} 3$ net site) is accessed by all faculty members in the network and by a growing number of staff and senior $\mathrm{PhD}$ students in the department. The features and potential uses of the $\mathrm{K}^{*} \mathrm{~T} 3$ net site will be discussed in this paper.

\section{Design}

\subsection{The $K^{*}$ T3net}

The purposes and functions of the $\mathrm{K}^{*} \mathrm{~T} 3$ net are defined in the Founding Statement, which is made available to all members through the homepage of the $\mathrm{K}^{*} \mathrm{~T} 3$ net site (Figure 1).

Figure 1. Founding Statement of the $\mathrm{K}^{*} \mathrm{~T} 3$ net as it appears on the $\mathrm{K}^{*} \mathrm{~T} 3$ net homepage.

\footnotetext{
A. The $\mathrm{K}^{*} 3$ net in the Department of Human Health and Nutritional Sciences is designed to support all department members who have some professional activities in research, scholarship or creative expression in the human health sciences that do NOT fall under the description of laboratory-based, discovery science. K*T3net includes the areas of translation, transfer and teaching of knowledge, skills and/or attributes in the health sciences with emphasis on the fields of nutritional and nutraceutical sciences and human kinesiology.

B. The $\mathrm{K}^{*} \mathrm{~T} 3$ net is designed to link the Department activities in this broad domain to similar groups currently forming in other departments/colleges on the University of Guelph and University of Guelph-Humber campuses - and to national and international organizations that support and promote these aspects of the collective academic endeavour.

C. The $\mathrm{K}^{*} \mathrm{~T} 3$ net is designed to foster excellence in these areas of research, scholarship and creative expression in the health sciences with emphasis on nutritional and nutraceutical sciences and human kinesiology.
}

All faculty, staff and graduate students within the department who were involved or interested in SoTL or SoKTT were invited to join $\mathrm{K}^{*} \mathrm{~T} 3$ net and new members are welcome at any time. The departmental chair, associate chair, graduate curriculum committee chair and undergraduate curriculum committee chair are members, in part to ensure that any consensus views from within the network activities and discussions can be readily made available to department members who choose not to participate in the network. Interested academics from outside the department and/or outside of the University of Guelph, who share expertise in teaching nutrition and nutraceutical science (NANS), human kinesiology, or a closely related field, have also been added as members of K*T3net. Currently, 
the membership of $\mathrm{K}^{*} \mathrm{~T} 3$ net includes faculty at the University of Guelph-Humber, York University and the University of Waterloo School of Pharmacy.

The Centre for Open Learning and Educational Support (OpenEd) is the central organization of teaching support at UoG. It provides assistance with educational development and has a broad focus on SoTL. They are available to assist all faculty and graduate students, regardless of their research background or other research practices, with the development of SoTL projects as well as the application of best practices in the classroom. The Office of Research at the University of Guelph is the central organization of knowledge translation and transfer (KTT) support for academic departments that do not have traditional extension divisions. It offers some assistance in SoKTT, particularly to holders of tri-council and Ontario Ministry of Agriculture, Food and Rural Affairs (OMAFRA) grants, however the main focus of this office is to provide KTT support. This office, along with the OpenEd, provide a great deal of general support in SoKTT and SoTL, however an ongoing issue for many faculty members is that they are often unable to attain discipline-specific support, and this can be a substantial barrier, especially for those who are new to this area of research. It can be extremely helpful, especially to a research new to the areas of SoTL and SoKTT, to be have access to individuals with a similar background who also have an understanding of how to approach a SoTL/SoKTT project in the field. This is especially important in the identification of potential collaborators, and the design of projects surrounding specific courses or subjects. For example, if a member were interested in examining the potential uses of virtual physiology laboratories in the classroom this may be out of the realm of expertise for an educational developer in OpenEd whose background is in the social sciences. A goal of the $\mathrm{K}^{*} \mathrm{~T} 3 \mathrm{net}$ is to provide discipline-specific, local support to its members and the department, while still functioning within the overarching umbrellas of the OpenEd and the Office of Research. The relationship of the $\mathrm{K}^{*} \mathrm{~T} 3$ net to central organizations which support SoTL and SoKTT is shown in Figure 2.

Figure 2. The relationship of $\mathrm{K}^{*} \mathrm{~T} 3$ net to central organizations which provide support in SoTL research within the University of Guelph. Blank shapes represent colleges and departments that are not involved in $\mathrm{K}^{*} \mathrm{~T} 3$ net. $\mathrm{MCB}$, Molecular and Cellular Biology; HHNS, Human Health and Nutritional Sciences; IB, Integrative Biology; CBS, College of Biological Sciences.

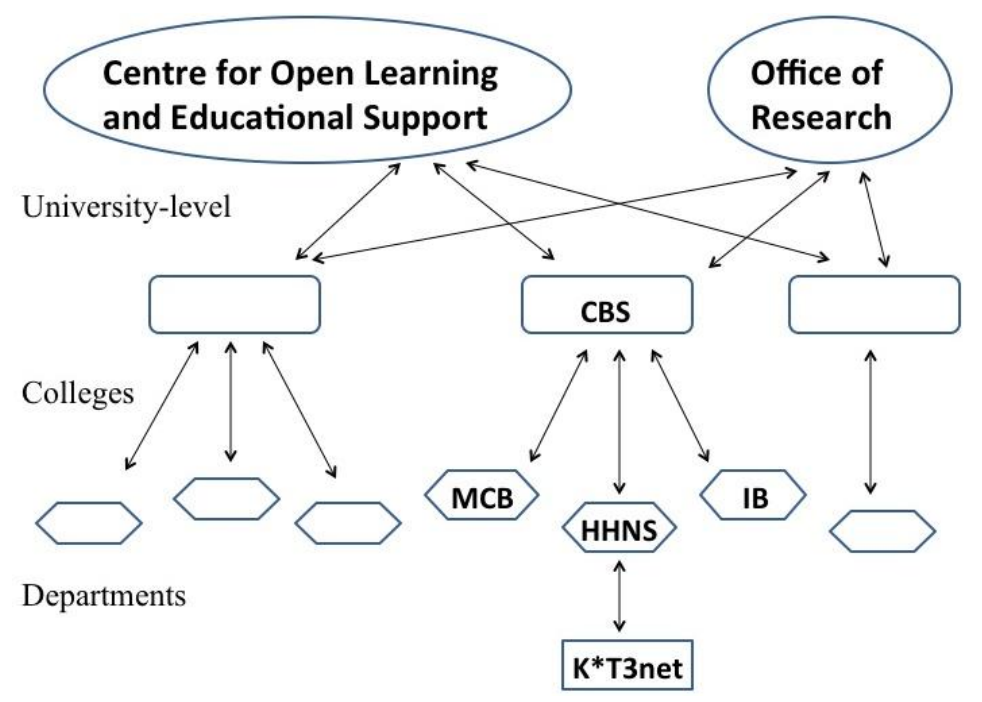




\subsection{The Virtual Common Space}

An LMS site was chosen as the common space of our departmental network. Desire2Learn (D2L) is an LMS used by over 650 institutions worldwide [11]. It is typically used as an online management system for individual courses (i.e., a course website). D2L was already in use as LMS for courses at UoG, however the use of an LMS site as the common space of a network of this nature is a novel application of the software system. The perceived benefits of choosing an LMS site as the common space for the $\mathrm{K}^{*} \mathrm{~T} 3$ net are:

- Ease and speed of set-up (total estimated set up time 10 people hours)

- No start up or maintenance costs, no space requirements

- Local professional support for the software application

- System sustainability (main use of the software is for UoG classes)

- Faculty, staff and student familiarity with the system

- Large and flexible-format storage capacity for multi-year use

- System security for information storage and discussions

- Ability to give users varying types of access (read-only, etc.).

- Ability to invite users who do not use D2L at their home institution

While many of the same benefits could be achieved through an open public forum, such as wiki or facebook, an LMS offers several advantages which these public sites can not. The added security of a private site like D2L, into which all members must be invited by an administrator of the site, protects personal information and discussion topics from being accessed by outside persons. This exclusivity helps ensure that members of the network feel comfortable sharing information related to their teaching and research. While public forums do increase the potential of other like-minded individuals finding the site and becoming involved, this is still outweighed by the many above-mentioned benefits of an LMS.

\subsection{Features of $K^{*}$ T3net Virtual Space}

When members first open the homepage of the $\mathrm{K}^{*} \mathrm{~T} 3$ net, they have simple access to all components of the virtual space. Some components are accessible through links on a navigation bar (i.e., discussion board, member list), however it was the goal of the founding members to make the majority of the content (including journal articles, conference proceedings, videos, and any other interesting information related to SoTL and SoKTT, see Section 2.3.1.) available directly on the homepage (Figure 3). The founding statement of $\mathrm{K}^{*} \mathrm{~T} 3$ net is posted centrally on the homepage, and it includes the aims as well as a link to the initial presentation proposing the network. The presentation provides a more detailed description of all that the network encompasses and is a useful tool for new members to learn of the network's origins and objectives. The new universal learning outcomes proposed by the University of Guelph (which include an enhanced focus throughout the institution on evidence-based teaching and learner-centredness) are also posted in this section of the homepage as they are an important resource which faculty and students may wish to refer to often, and also serves as the basis for the objectives of $\mathrm{K}^{*} \mathrm{~T} 3$ net. 
Figure 3. $\mathrm{K}^{*} \mathrm{~T} 3$ net homepage.

\section{Chronicle of Higher Educa... $\mid \nabla$ \\ The Chronicle of Higher Education | News News \\ - English Teachers Reject Use of Robots to Grade Student Writing \\ A statement from a national council is intended to prompt policy makers and test designers to think more fully about the pitfalls of machine scoring. \\ - Plan Advances at U. of Minnesota to Publish Average Grades \\ Under the proposal, the university would report on its Web site the average grades in academic programs, to provide context and to thwart grade inflation. \\ - Prominent Scholar Was Banned From Rutgers Campus \\ A dispute involving an evolutionary theorist escalated from claims of fraud to \\ accusations of violent behavior. \\ - Michael Sandel Responds}

\section{University Affairs $\mid \nabla$}

News | University Affairs

What's happening at Canadian universities ? News, analysis, reports and more.

- Four liberal arts colleges form new alliance

- Majority of Quebec universities say they

intend to leave CREPUQ

- City mayors come to the defence of their

universities

- Teacher ed programs begin to contract

\section{K*T3 Founding Statement $\mid \nabla \quad \checkmark$}

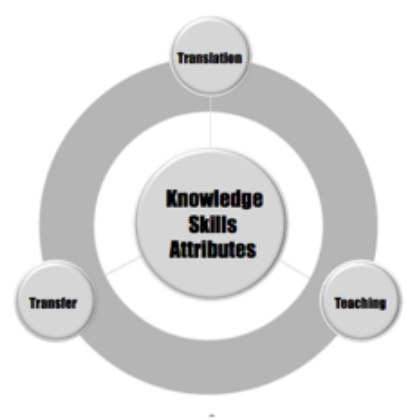

A. The $K * 3$ net in the Department of Human Health and Nutritional Sciences is designed to support all department members who have some professional activities in research, scholarship or creative expression in the human health sciences that do NOT fall under the description of laboratory-based, discovery science. K*T3net includes the areas of translation, transfer and teaching of knowledge, skills and/or attributes.

B. The $K * T 3 n e t$ is designed to link our Department activities in this broad domain to similar groups currently forming in other departments/colleges on the University of Guelph and University of Guelph-Humber campuses - and to national and international organizations that support and promote this aspect of the collective academic endeavour.

C. The $K^{*} T 3$ net is designed to foster excellence in these areas of research, scholarship and creative expression.

\section{Content Browser $\mid \nabla$}

Bookmarks Recently Visited

Home

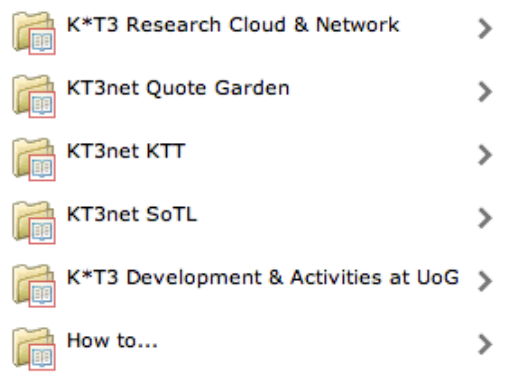

\section{News $\mid \nabla$}

\section{Creativity Teaching in the} Classroom Exploration

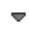

Posted Jul 6, 2012 2:50 PM

The $K * T 3$ net group is going to discuss a modified version of the McMaster University survey on the teaching of creativity in University programs and classes. If you would like to see the modified questionaire, and participate in our discussions,

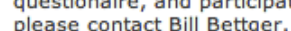

SoTL and KTT editing/peer review

Although there is a link in the navigation bar to the Content section of the site, this was also linked directly to the homepage so members can easily access new postings (Figure 3), as this was considered to be one of the most important components of the site. The details of the Content section are discussed in further detail below (see Content).

The final components of the homepage are the widgets for online news feeds regarding SoTL and SoKTT. We have used these widgets previously in undergraduate courses to provide news updates in relevant areas to biology students. The widgets are direct links to news feeds from education websites and are immediately updated when a new story is posted to the host site. At the time of publication there were two widgets on the K*T3net homepage: (1) The Chronicle of Higher Education, and (2) University Affairs. These widgets were added to keep K*T3net members aware of breaking news in higher education and occasionally provide interesting topics for discussion within the network.

\subsubsection{Content/Data Storage}

The Content section is subdivided into different topics, such as SoTL, KTT, and quotes, to make posting and retrieving information as simple as possible. All members are able to post content and this can include journal articles, conference proceedings or any other information that they find useful or interesting. As the site grows, the Content is further subdivided to allow more areas of interest to be added and easily accessed by members. For the more integrative topics, such as the Quote Garden, simple word documents are set up chronologically and members can open the document, add their new information, and repost, after which all members will see the updated version of the document when they enter the site. This was thought to be a more user-friendly method than adding a separate 
document for each quote since members can open the document and read a month's worth of information quickly instead of opening several separate documents.

Also included in the Content section is a single page document known as the Research Cloud. This document provides an organized subset of lists of the peer-reviewed journals currently in existence in several different areas of SoKTT and SoTL, including those with a very broad scope as well as those that are specific to science and health-related disciplines. This is meant to provide an initial picture of the information available, as well as where one could publish, for those members who are relatively new to this area of research.

\subsubsection{Discussion Board}

The Discussion Board is accessible through a link on the main navigation bar from the homepage. It is divided into Forums, each of which is focused on a specific area of discussion. Within each Forum, Topics are created and these represent each separate discussion that is taking place. Within a Discussion Topic members can post a new comment or reply to someone else's and these appear as either separate (new thought/comment) or combined (reply to a comment) threads (Figure 4). Importantly, a feature of D2L (and many other LMS platforms) allows members to comment anonymously, meaning that no other member can see who made that specific comment. We felt this was an important component of $\mathrm{K}^{*} \mathrm{~T} 3$ net as many of the members are supervisors, students or colleagues to several other members, and it was assumed that certain topics of discussion may arise where members may not feel comfortable attaching their identity to a comment. Thus the option of posting anonymously was determined to be invaluable to encourage an open environment where all members felt safe and comfortable sharing their thoughts.

Figure 4. Organization page of the discussion board (A), and an example of a discussion board thread (B) on the $\mathrm{K}^{*} \mathrm{~T} 3$ net virtual space.

\section{Quotes -}

\section{Knowledge Transfer \& Translation -}

\section{Scholarship of Teaching and Learning}

Hide Topics

Improved methods of teaching evaluation -

$\begin{array}{lll}0 & 9 & 0 \\ \text { Unread } & \text { Posts } & \text { Views }\end{array}$

(A) 
Figure 4. Cont.

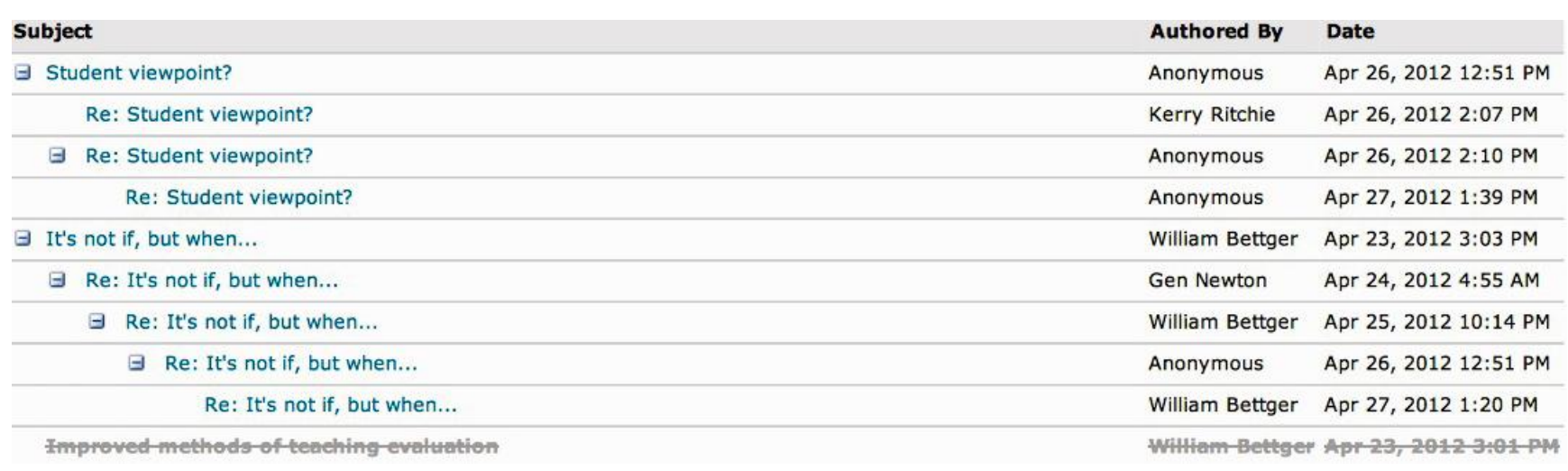

(B)

\subsubsection{Member Credentials, Activities and Ongoing Projects}

Under the "Classlist" section of the $\mathrm{K}^{*} \mathrm{~T} 3$ net site is the roster of members, along with their e-mail addresses and their "access level" on the site. Under the "Blog" section of each individual listed on the "Classlist", each member is being asked to place a short biographic sketch, followed by an indication of examples of completed projects and a list of ongoing and planning-stage projects in SoTL and/or SoKTT. This is designed to help the members of the $\mathrm{K}^{*} \mathrm{~T} 3$ net become more comfortable in reporting and promoting their activities in these domains; faculty traditionally do not report all of their activities in SoTL and SoKTT on their faculty activity report for tenure and promotion. Listing ongoing and planning stage projects will also encourage and indirectly facilitate collaboration between network members.

\subsubsection{Level of Access}

The traditional use of an LMS is as a course website; therefore the levels of access are organized by different levels of the teaching team as well as students and guests. All members of $\mathrm{K}^{*} \mathrm{~T} 3$ net were given teaching assistant-level access, meaning they are able to post and retrieve material in the Content section, create Discussion Board topics and comment on all Discussions. Two of the founding members were given instructor-level access, allowing them to alter the physical design of the site and add new members. They are also able to remove Discussion Board postings if necessary. This extra level of control was assigned to only two members as a means of maintaining the organization of the site as well as security. In the fall of 2012, MSc students and senior undergraduate students in a SoTL/SoKTT course will be given student level access (can post to the Discussion, but cannot create new Forums or Topics) to the site.

The virtual common space of the $\mathrm{K}^{*} \mathrm{~T} 3$ net has been operational for approximately six months at the time of submission. A number of developments over this time period suggest that the site is serving successfully as a local "teaching commons" [12] for SoTL and SoKTT, that is, a community of individuals with similar goals who can come to this virtual common space to share ideas and discuss related topics. As a result of the growing interest in SoTL and SoKTT in the department of Human Health and Nutritional Science, a new undergraduate course has been developed which will allow senior undergraduate students to conduct independent scholarship in these areas. The course, called 
"Teaching, Learning and Knowledge Transfer" will be an elective, upper year course and all students in the course will be invited to become members of $\mathrm{K}^{*} \mathrm{~T} 3$ net and have read-only access (student level) to the $\mathrm{K}^{*} \mathrm{~T} 3$ net site. Another novel use of the site is that students will be able to continue as members for the $\mathrm{K}^{*} \mathrm{~T} 3$ net, and have access to the site, for an extended period of time after completing the course. A graduate course is also being developed, as there is a rapidly expanding group of graduate students in the department who are involved in SoTL and SoKTT research.

\section{Future Direction and Conclusions}

The $\mathrm{K}^{*} \mathrm{~T} 3$ net has taken on several other functions since its inception. It has a central role in departmental projects on learning to "Bloom" (evaluate according to Bloom's taxonomy) examinations and other evaluative tools in the undergraduate classes of the department [13,14]. It is sponsoring a departmental effort to define "creativity" $[15,16]$, in the fields of nutritional and nutraceutical sciences and of human kinesiology. Outcomes of both of these activities will be posted and stored on the $\mathrm{K}^{*} \mathrm{~T} 3$ net site. An announcement has been posted on the site stating that network members are willing to help serve to evaluate research/scholarship in SoTL and SoKTT, including pre-reviewing manuscripts and grants that will be submitted. Members can also help review the scholarship quality of submissions in SoTL and SoKTT during tenure and promotion deliberations.

Faculty members and students who are interested in applying best practices in the classroom but who are not interested in taking on research projects in SoTL and SoKTT can also gain a great deal of knowledge and assistance through the $\mathrm{K}^{*} \mathrm{~T} 3$ net site. Members post many articles on discipline-specific teaching practices and some discussion threads have addressed specific examples of the application of new techniques in the classroom.

In addition to helping disseminate best practices within the department for teaching and outreach purposes, the $\mathrm{K}^{*} \mathrm{~T} 3$ net will also help guide collaborative research projects in SoTL and SoKTT. Joint applications for research projects are currently being prepared by network members, and it is a goal of the founding members to help connect members who are interested in similar areas of research in SoTL and SoKTT. Through the constant provision of new information and the involvement of members in discussions, new ideas and hypotheses are generated in this virtual common space, and potential collaborators are often identified through discussion postings or other posted content. It appears the $\mathrm{K}^{*} \mathrm{~T} 3$ net can provide the basic information and a virtual environment for faculty staff and students to move forward in research and scholarship as they strive to become "expert teachers" [17] in the classroom and beyond.

The K*T3net provides support to its faculty and student members in the areas of SoTL and SoKTT. It has improved knowledge translation of research in the areas of SoTL and SoKTT within the department and beyond, and has helped foster collaborations in these research areas. The virtual common space of the $\mathrm{K}^{*} \mathrm{~T} 3$ net has been very useful in providing a secure and convenient online meeting space for all members.

\section{Conflict of Interest}

The authors declare no conflict of interest. 


\section{References}

1. Mancuso, M. The Lighting of a Fire: Re-imagining the Undergraduate Learning Experience; Provost's White Paper, University of Guelph: Guelph, ON, Canada, 2005. Available online: http://www.uoguelph.ca/vpacademic/whitepaper/whitepaper.pdf (accessed on 5 January 2013).

2. Sullivan, W.M.; Rosin, M.S. A New Agenda for Higher Education: Shaping a Life of the Mind for Practice; The Carnegie Foundation for the Advancement of Teaching: Princeton, NJ, USA, 2008.

3. Miller, M.A. Editorial: The slow explosion. Change: The Magazine of Higher Learning 2012, 44, 4-5.

4. Summerlee, A.J.S.; Christensen Hughes, J. Pressures for Change and the Future of University Education. In Taking Stock: Research on Teaching and Learning in Higher Education; McGill-Queen's University Press: Montreal, QC, Canada, 2010; pp. 243-260.

5. Boyer, E.L. Scholarship Reconsidered: Priorities of the Professoriate, 1st ed.; The Carnegie Foundation for the Advancement of Teaching: Princeton, NJ, USA, 1990.

6. Arreola, R.A.; Theall, M.; Aleamoni, L.M. Beyond Scholarship: Recognizing the Multiple Roles of the Professoriate. Paper presented at the annual meeting of the American Educational Research Association, Chicago, IL, USA, April 2003.

7. Hutchings, P.; Huber, M.T.; Ciccone, A. The Scholarship of Teaching and Learning, Professional Growth and Faculty Development. In The Scholarship of Teaching and Learning Reconsidered; The Carnegie Foundation for the Advancement of Teaching: Stanford, CA, USA, 2011; pp. 45-68.

8. Weiman, C. Why Not Try a Scientific Approach to Science Education? In Taking Stock: Research on Teaching and Learning in Higher Education; McGill-Queen's University Press, Montreal, QC, Canada, 2010; pp. 175-190.

9. Christensen Hughes, J.; Mighty, J. A Call to Action: Barriers to Pedagogical Innovation and How to Overcome Them. In Taking Stock: Research on Teaching and Learning in Higher Education; MCGill-Queens University Press: Montreal, PC, Canada, 2010; pp. 261-277.

10. Shaxson, L.; Bielak, A.; Ahmed, I.; Brien, D.; Conant, B.; Fisher, C.; Gwyn, E.; Klerkx, L.; Middleton, A.; Morton, S.; Pant, L.; Phipps, D. Expanding Our Understanding of $\mathrm{K}^{*}$. In Proceedings of the UNU-INWEH K* 2012 Conference, Hamilton, ON, Canada, April 2012.

11. Cloud, S. Desire2Learn. In Proceedings of the 2012 VASS Virtual School Conference, Hampton, VA, USA, May 2012.

12. Huber, M.T.; Hutchings, P. The Advancement of Learning: Building the Teaching Commons; The Carnegie Foundation for the Advancement of Teaching: Princeton, NJ, USA, 2005.

13. Bloom, B.S. Taxonomy of Educational Objectives, Handbook I: The Cognitive Domain; David McKay Co. Inc.: New York, NY, USA, 1956.

14. O’Neill, A.; Birol, G.; Pollock, C.A. Report on the Implementation of the Blooming Biology Tool: Aligning Course Learning Outcomes with Assessments and Promoting Consistency in a Large Multi-Section First-Year Biology Course. In The Canadian Journal for the Scholarship of Teaching and Learning, 2010, Volume 1, Issue 1, Article 8.

15. Martin, P. Making Space for Creativity; Creativity Centre, University of Brighton: Brighton, UK, 2010. 
16. Sternberg, R.J. Teach Creativity, Not Memorization. In The Chronicle of Higher Education. 28 July 2012. Available online: http://chronicle.com/article/Teach-Creativity-Not/124879/ (accessed on 8 January 2013).

17. Carey, T. Three Perspectives on Teaching Knowledge: Craft, Professional, and Scientific. In: Taking Stock: Research on Teaching and Learning in Higher Education; McGill-Queens University Press: Montreal, PC, Canada, 2010; pp. 215-226.

(C) 2013 by the authors; licensee MDPI, Basel, Switzerland. This article is an open access article distributed under the terms and conditions of the Creative Commons Attribution license (http://creativecommons.org/licenses/by/3.0/). 